\title{
Retraction Note to: Day of the year-based prediction of horizontal global solar radiation by a neural network auto-regressive model
}

\author{
Abdullah Gani ${ }^{1} \cdot$ Kasra Mohammadi ${ }^{2}$. Shahaboddin Shamshirband ${ }^{1} \cdot$ Hossein Khorasanizadeh $^{2}$. \\ Amir Seyed Danesh ${ }^{5} \cdot$ Jamshid Piri $^{3} \cdot$ Zuraini Ismail $^{4} \cdot$ Mazdak Zamani $^{4}$
}

Published online: 9 March 2020

(C) Springer-Verlag GmbH Austria, part of Springer Nature 2020

\section{Retraction Note to: Theor Appl Climatol (2016) 125:679-689 https://doi.org/10.1007/s00704-015-1533-8}

The Editor-in-Chief has retracted this article [1] because validity of the content of this article cannot be verified. This article showed evidence of substantial text overlap (most notably with the articles cited $[2,3]$ ) and authorship manipulation. Shahaboddin Shamshirband disagrees with this retraction. Authors Abdullah Gani Kasra Mohammadi, Hossein Khorasanizadeh, Amir Seyed Danesh, Jamshid Piri, Zuraini Ismail, Mazdak Zamani have not responded to correspondence about this retraction.
[1] Gani, A., Mohammadi, K., Shamshirband, S. et al. Theor Appl Climatol (2016) 125: 679. https://doi.org/10.1007/ s00704-015-1533-8

[2] "Hybrid auto-regressive neural network model for estimating global solar radiation in Bandar Abbas, Iran" by Shahaboddin Shamshirband, Kasra Mohammadi, Jamshid Piri, Dalibor Petković, Ahmad Karim; Environmental Earth Sciences; 75:172

[3] "Potential of adaptive neuro-fuzzy system for prediction of daily global solar radiation by day of the year" by Kasra Mohammadi, Shahaboddin Shamshirband, Chong Wen Tong, Khubaib Amjad Alam, Dalibor Petković. Energy Conversion and Management, Volume 93, 15 March 2015, Pages 406-413

The online version of the original article can be found at https://doi.org/ 10.1007/s00704-015-1533-8

Kasra Mohammadi

kasra278@yahoo.com

Shahaboddin Shamshirband

shamshirband@um.edu.my

Hossein Khorasanizadeh

khorasan@kashanu.ac.ir

1 Department of Computer System and Technology, Faculty of Computer Science and Information Technology, University of Malaya, 50603 Kuala Lumpur, Malaysia
2 Faculty of Mechanical Engineering, University of Kashan, Kashan, Iran

3 Department of Water Engineering, Soil and Water College, University of Zabol, Zabol, IR, Iran

4 Advanced Informatics School, Universiti Teknologi Malaysia, Johor Bahru, Malaysia

5 Department of Software Engineering, Faculty of Computer Science and Information Technology, Uiversity of Malaya, 50603 Kuala Lumpur, Malaysia 